\title{
Preventing the progression of diabetic kidney disease
}

\author{
Sheikh Salahuddin Ahmed \\ Department of Internal medicine, Bangladesh Institute of Health Sciences (BIHS), Dhaka, Bangladesh
}

Email address:

drsksalahahmed@yahoo.com

To cite this article:

Sheikh Salahuddin Ahmed. Preventing the Progression of Diabetic Kidney Disease. American Journal of Internal Medicine. Vol. 2, No. 2, 2014, pp. 26-33. doi: 10.11648/j.ajim.20140202.14

\begin{abstract}
Diabetic kidney disease (DKD) is a progressive condition and is an important cause of end-stage renal disease (ESRD) causing increased morbidity and mortality. The objective of this review article is to discuss about recognition and treatment of early DKD to prevent its progression. Informations have been gathered from related clinical studies, research works, articles, abstracts, and guidelines of different organizations published in various journals. Microalbuminuria describes the urinary excretion of small amounts of albumin which identifies the early stage of DKD. In addition to an earliest marker of kidney damage, microalbuminuria is an established high risk factor for cardiovascular morbidity and mortality. Patients with microalbuminuria who progress to macroalbuminuria are likely to progress to ESRD. There is general agreement that people with diabetes should be screened regularly to detect early markers of kidney damage. Albumin creatinine ratio in a morning urine sample is the preferred method of detecting microalbuminuria in diabetes. There is strong evidence that a number of interventions if initiated at early stage of DKD reduces the risk and slows the progression of kidney damage. People with diabetes and microalbuminuria should be treated with a multifactorial intervention approach to retard the progression of DKD. Studies have clearly demonstrated that the use of angiotensin converting enzyme inhibitors or angiotensin 2 receptor blockers with improved glycemic control, blood pressure control, lipid lowering, aspirin, smoking cessation, exercise programs and dietary intervention reduced the development of overt nephropathy and ESRD.
\end{abstract}

Keywords: Diabetic Kidney Disease, Macroalbuminuria, Microalbuminuria

\section{Introduction}

Diabetes has been found to be the leading cause of ESRD in many countries; this is mainly due to the facts that diabetes, particularly type 2, has increased in prevalence; longevity has also increased from improved treatment of diabetes with better cardiovascular protective measures [1, 2]. In South Asian countries including Bangladesh, diabetes was found to be second leading cause of ESRD about a decade ago $[3,4]$. Microalbuminuria is the earliest marker of DKD and a risk factor for the development of cardiovascular morbidity and mortality $[5,6,7]$. DKD is a progressive condition: patients with microalbuminuria who progress to macroalbuminuria are likely to progress to ESRD [8]. To sustain life, ESRD requires renal replacement therapy (RRT) that includes maintenance dialysis or renal transplantation. But most of the people in low income country like Bangladesh cannot afford the treatment cost as dialysis or renal transplantation is very expensive. However, there is strong evidence that a number of interventions if initiated at early stage of DKD reduces the risk and slows the progression of kidney damage [9]. Therefore there is general agreement that people with diabetes should be screened regularly to detect early marker of kidney damage and receive treatment [2].

\subsection{Microalbuminuria \& Macroalbuminuria}

The National Kidney Foundation (NKF), an organization in the US, defines microalbuminuria as excretion of 30-300 $\mathrm{mg}$ of albumin in a 24 hour urine collection sample (equivalent to albumin excretion rate of $20-200 \mu \mathrm{g} / \mathrm{min}$ in a timed collection of urine; or albumin creatinine ratio [ACR] 30-300 mg/g without regard to age \& sex in a random or spot sample of urine), with values $>300 \mathrm{mg} / 24$ hour being defined as macroalbuminuria [10]. Macroalbuminuria is also known as clinical albuminuria or proteinuria (as it correlates with a urinary protein excretion $0.5 \mathrm{~g} / 24$ hour) $[1,11]$. So it is now well understood that urinary albumin excretion can be measured by three methods: (a) measurement of albumin in 24 hour urine collection; (b) measurement of ACR in a random or spot urine collection and (c) measurement of albumin excretion rate (AER) in timed collection (e.g., 4 hour or overnight). The ACR is a useful surrogate marker for proteinuria and is used instead of the time consuming 24 hour 
urine collection. ACR is the recommended method for screening microalbuminuria in people with diabetes [9, 12]. Microalbuminuria can be detected by radioimmunoassay but dipsticks test is usually negative for microalbuminuria [13]. If assays for microalbuminuria are not readily available, screening with dipsticks may be carried out. Positive dipstick tests should be confirmed in the laboratory by measuring the ACR preferably on an early morning urine sample [11]. There is also marked day to day variation in albumin excretion, so at least two of three collections done in a 3 to 6 month period should show elevated levels before designating a patient as having microalbuminuria [1,9]. Canadian [14] and Australian [15] guidelines confirm microalbuminuria if at least two of three tests (including the screening test) are positive measured within 3 months. The first abnormal result of spot urine test should be confirmed on an early morning sample. If AER or ACR screening is positive for macroalbuminuria, a 24 hour urine collection should be performed for quantitation of protein excretion [15].

\subsection{Emerging Biomarkers for Kidney Disease}

Currently used measures to assess kidney function and damage are largely inadequate. Proteinuria is the most sensitive marker of CKD progression in clinical practice, especially when combined with eGFR, but proteinuria has some limitations as a biomarker of CKD progression and response to interventions [16]. Recently sensitive biomarkers have been identified that are able to detect kidney damage earlier than is currently possible, can reflect kidney function and predict progression or regression of CKD. The most promising among them include Cystatin C, $\beta$-Trace protein (BTP), Neutrophil gelatinase-associated lipocalin (NGAL), $N$-Acetyl- $\beta$-O-glucosaminidase (NAG), Kidney injury molecule-1 (KIM-1), Liver-type fatty acid binding protein (L-FABP), Podocin and Nephrin.

Cystatin-C has recently emerged as a reliable biomarker of renal function and $\mathrm{CKD}$ progression. Cystatin-C is particularly sensitive at detecting changes in kidney function when renal impairment is mild [17], and is better than creatinine for assessment of acute kidney injury (AKI) [18]. In one study, serum Cystatin $\mathrm{C}$ predicted CKD progression [19]. BTP is a more sensitive indicator of glomerular filtration than serum creatinine [20]. In a report from a study, BTP also provided reliable risk prediction for CKD progression [19]. Serum and urinary NGAL have been identified as early biomarkers of AKI [21]. In addition, recent evidence suggests that NGAL may even be involved as a mediator of CKD progression [22]. Both urinary and serum NGAL levels also increased in parallel in a study of diabetic patients, suggesting that NGAL may play an important role in the pathophysiology of renal adaptation to diabetes and associated nephropathy [23]. NGAL has the greatest promise as a biomarker of CKD progression. A recent study in T1DM found that lower levels of urinary NAG were associated with the regression of microalbuminuria [24]. KIM-1 is increased in the urine in AKI [25]. Experimental studies suggest that KIM-1 may be an indicator of AKI to CKD transition [26]. Lower urinary levels of KIM-1 were associated with the regression of microalbuminuria in patients with T1DM [24]. In CKD, increasing urine levels of L-FABP correlate with declining renal function [27]. L-FABP is expressed in proximal tubular cells and is a biomarker of inflammation investigated in diabetes, diabetic nephropathy, hypertension, and early CKD [28, 29, 30]. New biomarkers of renal glomerular podocyte damage have been discovered which include urinary Nephrin and Podocin [31]. Increased urinary levels of Nephrin and Podocin have been detected in patients with diabetic nephropathy [31]. Currently, none of these are ready for routine clinical use. Additional large, multicenter prospective studies are needed to validate the biomarkers for implementation into routine CKD management. Serum creatinine and creatinine clearance are well-established biomarkers of renal function that can be measured cheaply and easily.

\subsection{Diabetic Kidney Disease}

The term DKD refers to a presumptive diagnosis of kidney disease caused by diabetes [10]. In diabetes, chronic kidney disease (CKD) is diagnosed on the basis of a raised urine albumin or a reduced glomerular filtration rate or GFR $(<60$ $\mathrm{ml} / \mathrm{min} / 1.73 \mathrm{~m} 2$ ) [2]. In the absence of another identifiable or treatable cause of kidney disease, patients with diabetes and CKD should be treated as if they have DKD (10). DKD traditionally termed "diabetic nephropathy," is a clinical diagnosis that historically has been based on the findings of albuminuria with no other cause, in a person with diabetes [10]. Microalbuminuria indicates the early stages of DKD [5, $6,32]$. The term diabetic glomerulopathy should be reserved for biopsy-proven kidney disease caused by diabetes [10]. In most individuals the diagnosis of DKD is made clinically, as biopsy may not alter management of such patient. However a kidney biopsy may be required in some patients with diabetes and CKD to determine the underlying cause; and referral to a physician experienced in the care of kidney disease should be considered when there is uncertainty about the etiology of kidney disease (patients having heavy proteinuria, hematuria, active urine sediment, absence of retinopathy, rapid decline in GFR, resistant hypertension) [9].

\section{Natural history of Diabetic Kidney Disease}

The natural history of DKD is characterized by a sequence of events that was initially defined for patients with type 1 diabetes (T1DM), but appears similar in type 2 diabetes (T2DM). The typical early clinical presentation of DKD is microalbuminuria, which generally appears 5-15 years after the patient is diagnosed with diabetes mellitus [33]. This is the earliest clinical evidence of DKD, and patients with microalbuminuria are referred to as having incipient nephropathy [1]. At this stage of CKD dipstick tests for proteinuria are typically negative. Without specific 
interventions, $20-40 \%$ of T2DM patients with microalbuminuria progress to overt nephropathy by developing macroalbuminuria or clinical albuminuria $(>300$ $\mathrm{mg} / 24 \mathrm{~h}$ ); there is steady decline of GFR, rise of blood pressure and the pathological changes in the kidneys are likely irreversible $[1,15]$. ESRD develops in $50 \%$ of type 1 diabetic individuals with overt nephropathy within 10 years and in $>75 \%$ by 20 years [1]. However, up to $30 \%$ of people with T2DM who have a GFR $<60 \mathrm{ml} / \mathrm{min} / 1.73 \mathrm{~m} 2$ (i.e. stage 3 CKD) may remain normoalbuminuric [34]. For this group the natural history of kidney disease has yet to be defined. Therefore, in diabetes CKD may develop in the absence of abnormalities in albumin excretion [15].

\section{Screening for Diabetic Kidney Disease}

Screening for DKD should include measurement of urinary albumin, measurement of serum creatinine and calculation of estimated GFR (eGFR) [1, 2, 10]. Measurement of serum creatinine and eGFR is required in addition to measurement for albuminuria because a significant proportion of people with DM develop CKD in the absence of albuminuria $[2,10$, $15,35]$. The NKF \& the American Diabetic Association (ADA) recommends to commence initial screening at 5 years after the diagnosis of T1DM or from diagnosis of T2DM; and thereafter annually $[1,10]$. Microalbuminuria rarely occurs with short duration of T1DM [1]. There is currently no proven role of screening for microalbuminuria in patients who do not have diabetes [11]. Patients should not be screened during intercurrent illness or when other factors are present influencing proteinuria (e.g., urinary tract infection, congestive heart failure, acute febrile illness, menstruation or vaginal discharge). The best possible metabolic control of diabetes should be achieved before investigating patients for microalbuminuria [11]. ACR should be measured using a morning urine sample because studies have shown that it correlates best with 24 hour protein excretion, and an early morning sample is required for the diagnosis of orthostatic (postural) proteinuria. Where a first void specimen is not possible, a random urine specimen is acceptable [2,11]. As a significant proportion of people with T2DM may have or develop CKD in the absence of albuminuria, estimation of GFR is required in addition to screening for albuminuria [15]. GFR is most commonly estimated using the Modification of Diet in Renal Disease (MDRD) equation which is based on serum creatinine, age, sex and race. The MDRD formula tends to underestimate GFR at levels greater than $60 \mathrm{~mL} / \mathrm{min}$ but is more accurate at lower levels [15].

\section{Interventions to Prevent Progression of Diabetic Kidney Disease}

People with diabetes and microalbuminuria should be treated with a multifactorial intervention approach. Treatments that lower urinary albumin excretion slow progression of DKD and improve clinical outcomes.
Therefore albuminuria reduction should be considered a treatment target in DKD.

\subsection{Use of Angiotensin-Converting Enzyme (ACE) Inhibitor or an Angiotensin-2 Receptor Blocker (ARB) Drugs}

ACE inhibitor/ARB delay progression from micro- to macro-albuminuria in people with T2DM and hypertension. A meta-analysis of several trials has shown that ACE inhibitors and ARBs can cause microalbuminuria to regress to no albuminuria in diabetes [36, 37]. Systematic review also reveals that there is a reduction in the rate of progression of microalbuminuria to macroalbuminuria in patients with diabetes treated with ACE inhibitors or ARBs [36-38]. Another meta-analysis of 16 trials (7,603 patients) demonstrated that ACE inhibitors prevented the development of DKD in patients with no microalbuminuria (albumin excretion $<30 \mathrm{mg} /$ day) at baseline. This effect appeared to be present in patients with or without hypertension, patients with T1DM or T2DM, and patients with or without normal GFR [39]. Treatment with an ACE inhibitors and ARBs should be considered even in normotensive people with diabetes and microalbuminuria [10]. ACE inhibitors and ARBs confer both cardioprotective and renoprotective effects. ACE inhibitors and ARBs preferentially lower intra-glomerular pressure and reduce proteinuria. People with T1DM and microalbuminuria should be treated with an ACE inhibitor irrespective of blood pressure (BP) [6]. People with T2DM and microalbuminuria should be treated with an ACE inhibitor or an ARB irrespective of BP [6]. ACE-inhibitors and ARBs have also been shown to delay progression of nephropathy in those who have macroalbuminuria and renal insufficiency (serum creatinine $>1.5 \mathrm{mg} / \mathrm{dl}$ ) [2]. Therefore ACE inhibitors or ARBs should be used in individuals with micro- or macroalbuminuria, titrated to maximum tolerated dose [2]. In the absence of an anti-proteinuric response with either agent alone, combined treatment with both ACE inhibitors and ARBs has been considered. The combination is associated with a greater reduction in proteinuria compared to either agent alone. In one study, combination therapy with candesartan (ARB) and lisinopril (ACE inhibitor) was more effective than treatment with either drug alone in reducing BP and microalbuminuria in patients with T2DM, hypertension, and microalbuminuria [40]. Combinations of drugs that block the renin-angiotensin-aldosterone system (e.g., an ACE inhibitor plus an $\mathrm{ARB}$, or a direct renin inhibitor) have been shown by other 2 studies to provide additional lowering of albuminuria [41, 42]. However, a recent randomized, controlled study found such combinations to provide no additional cardiovascular benefit but with higher adverse event rates [43], and their effects on major renal outcomes have not yet been proven. It is uncertain, therefore, whether the ACE inhibitor plus ARB therapy can be advised routinely. National Kidney Foundation does not recommend the use of combination of ACE-inhibitor and ARBs as a dual 
blockade of the renin-angiotensin system at present (44). One clinical trial has shown an increase in adverse events, particularly impaired kidney function and hyperkalemia, compared to either agent alone, despite a reduction in albuminuria using combination therapy $(45,46)$.

\subsection{Diabetes Control}

Effective control of blood glucose has been shown to reduce the progression of CKD in people with diabetes. The Diabetes Control and Complications Trial (DCCT) conducted in US [47], and the United Kingdom Prospective Diabetes Study (UKPDS) [48] have definitively shown that intensive diabetes therapy can significantly reduce the risk of the development of microalbuminuria and overt nephropathy in people with diabetes. Studies have shown that the glycosylated hemoglobin (HbA1c) level correlates with loss of renal function and that effective glycemic control prevents the onset and delays the progression of kidney disease in both T1DM and T2DM [48-51]. Therefore in diabetes, glycemic control should be optimized to prevent or delay progression of the microvascular complications of diabetes, including DKD. The ADA [52, 53] \& Canadian guidelines [14] recommends that plasma values for preprandial glucose be kept in the $5.0-7.2 \mathrm{mmol} / \mathrm{L}(90-130 \mathrm{mg} / \mathrm{dL})$ range and $\mathrm{HbA} 1 \mathrm{c}$ should be $<7 \%$ to prevent progression of CKD in patients with DM.

\subsection{Hypertension Control}

Elevated BP is strongly associated with the development of albuminuria in people with diabetes. BP lowering reduces proteinuria. The UKPDS provided strong evidence that control of BP can reduce the development of nephropathy [54]. In patients with underlying nephropathy, treatment with ACE inhibitors or ARBs is also indicated as part of initial therapy. ACE inhibitors have been shown to reduce major cardiovascular outcomes (i.e., myocardial infarction, stroke, death) in patients with diabetes [55], thus further supporting the use of these agents in patients with albuminuria, a cardiovascular risk factor. Many studies have shown that in hypertensive patients with T1DM, ACE inhibitors can reduce the level of albuminuria and the rate of progression of renal disease to a greater degree than other antihypertensive agents that lower blood pressure by an equal amount [54]. In accordance with the "Standards of Medical Care in Diabetes Mellitus," the position statement on "Hypertension Management in Adults with Diabetes," the primary goal of therapy for nonpregnant diabetic patients $\geq 18$ years of age is to decrease BP to and maintain it at $<130 \mathrm{mmHg}$ systolic and $<80$ $\mathrm{mmHg}$ diastolic [9]. When ACE-inhibitor therapy is started, some patients with CKD may have an initial decrease in GFR (usually less than $10 \mathrm{~mL}$ per minute per $1.73 \mathrm{~m} 2$ ), a mild increase in the serum creatinine concentration (less than 20 percent of the baseline value), and a mild increase in the potassium level (usually less than $0.5 \mathrm{mmol}$ per L) [56]. Therefore, in people with CKD, serum creatinine and potassium levels should be measured and the GFR should be estimated before starting ACE inhibitor/ARB therapy. These measurements should be repeated between 1 and 2 weeks after starting ACE inhibitor/ARB therapy and after each dose increase [12]. ACE inhibitor/ARB therapy should not normally be started if the pretreatment serum potassium concentration is significantly above the normal reference range (typically more than $5.0 \mathrm{mmol} / \mathrm{L}$ ) [12]. Other drugs, such as diuretics, calcium channel blockers, and $\beta$-blockers, should be used as additional therapy to further lower BP in patients already treated with $\mathrm{ACE}$ inhibitors or ARBs, or as alternate therapy in the rare individual unable to tolerate ACE inhibitors or ARBs [9].

\subsection{Limitation of Protein Intake}

Some studies in patients with varying stages of DKD have shown that dietary protein restriction helps slow the progression of albuminuria, GFR decline, and occurrence of ESRD [57, 58]. For non-diabetic and diabetic patients with CKD stage 4, two systematic reviews and one meta-analysis suggested that, in comparison to other treatments, there was a modest benefit associated with restricting protein leading to a delay in CKD progression [59, 60]. The ADA recommends reduction of protein intake to $0.8-1.0 \mathrm{~g} / \mathrm{kg}$ body $\mathrm{wt} /$ day in individuals with diabetes and the earlier stages of CKD and to $0.8 \mathrm{~g} / \mathrm{kg}$ body wt/day in the later stages of CKD that may improve renal function [9]. The Scottish guidelines do not recommend high protein intake $(>1.0 \mathrm{~g} / \mathrm{kg})$ in patients with stage 4 chronic kidney disease [6]. The International Diabetes Federation (IDF) advises limiting protein intake to $1 \mathrm{~g} / \mathrm{kg}$ daily if proteinuria [2]. High protein intakes are associated with high phosphate intakes as foods that contain protein also tend to contain phosphate. It would appear prudent to avoid high protein intakes in stage $4 \mathrm{CKD}$ patients when hyperphosphatemia is prevalent [6]. Dietary protein restriction should be considered particularly in patients whose nephropathy seems to be progressing despite optimal glucose and blood pressure control and use of ACE inhibitor and/or ARBs [58].

\subsection{Other Approaches}

People with diabetes should be informed that smoking increases the risk of CKD and cardiovascular disease, an individual's smoking cessation is an important recommendation irrespective of CKD. Microalbuminuria is a well-established marker of increased cardiovascular risk [2, 5]. The ADA recommends aspirin therapy (75-162 mg/day) as a primary prevention strategy in those with diabetes at increased CVD risk which also includes most men $>50$ years of age or women $>60$ years of age who have albuminuria [9]. Abnormal blood lipid profiles are strongly associated with the progression and severity of CKD in people with diabetes. Dyslipidemia may contribute to the development and progression of DKD by causing intrarenal arteriosclerosis or direct toxicity to renal cells $[61,62]$. There is some preliminary evidence to suggest that lowering cholesterol may also reduce the level of proteinuria. A recent meta-analysis of 13 small studies showed that lipid reduction preserves GFR and reduces proteinuria [63]. Given the strong association between dyslipidemia and 
cardiovascular disease, management of blood lipid in DM is recommended irrespective of the presence of indicators of CKD. NKF recommends using LDL-C lowering medicines, such as statins or statin/ezetimibe combination, to reduce risk of major atherosclerotic events in patients with diabetes and CKD [44].

\section{Discussion}

Persistent microalbuminuria in diabetes has been associated with progression to overt nephropathy and ultimately to ESRD; and an increased risk of atherosclerosis and cardiovascular morbidity and mortality; neither the mechanism of proteinuria nor an explanation of these associations has yet been established [13]. Therefore there is general agreement that people with diabetes should be screened regularly to detect early indications of kidney damage and receive treatment. The ACR is the preferred method of detecting albuminuria but cut-off values differ somewhat between guidelines. The ADA has defined microalbuminuria as excretion of $30-299 \mathrm{mg}$ of albumin in a 24 hour urine collection (equivalent to albumin excretion rate of $20-199 \mu \mathrm{g} / \mathrm{min}$ in a timed collection of urine; or ACR $30-299 \mu \mathrm{g} / \mathrm{mg}$ creatinine in a random or spot sample of urine irrespective of sex), with values $\geq 300 \mathrm{mg} / 24$ hour being defined as macroalbuminuria [1]. Microalbuminuria has been defined as 2.5-30.0 mg/ mmol (men) and 3.5-30.0 $\mathrm{mg} / \mathrm{mmol}$ (women) in Europe [6, 11], 2.0-20.0 mg/mmol (men) and 2.8-28.0 (women) in Canada [64], and 2.5-25.0 $\mathrm{mg} / \mathrm{mmol}$ (men) and 3.5-35.0 (women) in Australia [15] and macroalbuminuria as $>20 / 28 \mathrm{mg} / \mathrm{mmol},>30 \mathrm{mg} / \mathrm{mmol}$ and $>25 / 35 \mathrm{mg} / \mathrm{mmol}$ respectively [2]. The National Institute for Health and Clinical Excellence (NICE) guideline defines microalbuminuria as ACR 2.5 to 25.0 $\mathrm{mg} / \mathrm{mmol}$ in men and ACR 3.5 to $35 \mathrm{mg} / \mathrm{mmol}$ in women [12]. The IDF considers microalbuminuria ACR $>2.5 \mathrm{mg} /$ $\mathrm{mmol}$ in men, $>3.5 \mathrm{mg} / \mathrm{mmol}$ in women. An ACR $>30$ $\mathrm{mg} / \mathrm{mmol}$ indicates macroalbuminuria [2].

The criteria for diagnosis of DKD vary somewhat between different guidelines. The ADA considers microalbuminuria to be the earliest stage of diabetic nephropathy in T1DM and a marker for development of nephropathy in T2DM [9]. The NKF considers CKD attributable to DKD in the presence of: (1) macroalbuminuria or microalbuminuria plus retinopathy, and (2) in people with T1DM, in the presence of microalbuminuria plus duration of diabetes longer than 10 years [10]. In Scotland DKD is usually classified, on the basis of the extent of urine protein excretion, as either microalbuminuria or nephropathy (having macroalbuminuria) [2]. A patient with DKD having macroalbuminuria with or without a raised serum creatinine level represents a more severe and established form of renal disease and is more predictive of total mortality, cardiovascular mortality and ESRD than microalbuminuria [2].

\section{Conclusion}

Interventions initiated at early stage of DKD may postpone or prevent overt nephropathy. Studies have clearly demonstrated the benefits of a multifactorial approach that include improved glycemic control, BP control, lipid lowering, aspirin, smoking cessation, exercise programs and dietary intervention. $[65,66]$. These interventions reduced the development of overt nephropathy and ESRD. Proteinuria reduction should be a treatment target regardless of baseline urinary protein excretion. The benefits of ACE inhibitor or ARB therapy for people with diabetes with microalbuminuria, irrespective of the presence of hypertension or CKD stage, are well established. ACE inhibitors and ARBs are effective at reducing proteinuria, slowing the decline in GFR and retarding the progression of kidney disease in both diabetic and non-diabetic patients with or without hypertension. Therefore treatment initiation is recommend with ACE inhibitors or ARBs unless contraindicated in diabetes having persistent microalbuminuria (early or incipient nephropathy) or macroalbuminuria (overt nephropathy) independently of the presence of hypertension.

\section{References}

[1] Molitch ME, DeFronzo RA, Franz MJ, Keane WF, Mogensen CE, Parving HH, et al. Nephropathy in Diabetes. American Diabetes Association Position Statement. Diabetes Care 2004 Jan;27(Suppl 1):S79-83.

[2] International Diabetes Federation, 2012 Clinical Guidelines Task Force Global Guideline for Type 2 Diabetes. Available from:http://www.societate-diabet.ro/pdf/Global-Guideline-f or-Type-2-Diabetes-IDF-2012.pdf

[3] Rashid HU: Bangladesh Renal Registry Report 1986-1996. Bang Renal J. 2002;21(1): 25-28.

[4] Sakhuja V, Sud K. End Stage Renal Disease in India and Pakistan: burden of disease and management issues. Kidney Int. Suppl 2002;83:S115-118.

[5] Garg JP, Bakris GL. Microalbuminuria: marker of vascular dysfunction, risk factor or cardiovascular disease. Vasc Med 2002;7:35-43.

[6] Scottish Intercollegiate Guidelines Network. Management of diabetes. A national clinical guideline. March 2010. Available from http://www.sign.ac.uk/pdf/sign116.pdf

[7] Klausen K, Borch-Johnsen K, Feldt-Rasmussen B, Jensen G, Clausen $\mathrm{P}$, Scharling $\mathrm{H}$, et al. Very low levels of microalbuminuria are associated with increased risk of coronary heart disease and death independently of renal function, hypertension, and diabetes. Circulation 2004;110:32-35.

[8] Gall MA, Hougaard P, Borch-Johnsen K, Parving HH. Risk factors for development of incipient and overt diabetic nephropathy in patients with non-insulin dependent diabetes mellitus: prospective, observational study. BMJ 1997;314:783-788. 
[9] American Diabetes Association. Standards of medical care in diabetes. Diabetes Care 2013;36(Suppl 1):S11-S66.

[10] National Kidney Foundation. K/DOQI Clinical Practice Guidelines and Clinical Practice Recommendations for Diabetes and Chronic Kidney Disease. Am J Kidney Dis. 2007;49(2 suppl 2):S1-179. Available from http://www.kidney.org/professionals/KDOQI/guideline_diab etes/

[11] UK CKD guidelines consultation draft 9th December 2005. Available

from http://www.kidney.org.uk/main/guidelines/UKCKD_guideli nes_consultation_draft.pdf

[12] NICE clinical guidelines. CG73 Chronic kidney disease. Early identification and management of chronic kidney disease in adults in primary and secondary care. Issued: September 2008. Available from http://publications.nice.org.uk/chronic-kidney-disease-cg73

[13] Goddard J, Turner AN, Stewart LH. Kidney and urinary tract disease. In: Colledge NR, Walker BR S \& Ralston SH. Davidson's Principle and Practice of Medicine. 21st International ed. Churchill Livingstone Elsevier;2010:pp480-496.

[14] Levin A, Hemmelgarn B, Culleton B, Tobe S, McFarlane P, Ruzicka M, et al. Guidelines for the management of chronic kidney disease. CMAJ 2008;179(11):1154-62.

[15] Chadban S, Howell M, Twigg S, Thomas M, Jerums G, Alan C, et al. National Evidence Based Guideline for Diagnosis, Prevention and Management of Chronic Kidney Disease in Type 2 Diabetes. Diabetes Australia and the NHMRC, Canberra 2009

[16] Levey AS, Cattran D, Friedman A Miller WG, Sedor J, Tuttle $\mathrm{K}$ et al. Proteinuria as a surrogate outcome in CKD: report of a scientific workshop sponsored by the National Kidney Foundation and the US Food and Drug Administration. Am J Kidney Dis 2009; 54: 205-226.

[17] Mussap M, Dalla Vestra M, Fioretto P, Saller A, Varagnolo M, Nosadini $\mathrm{R}$ et al. Cystatin $\mathrm{C}$ is a more sensitive marker than creatinine for the estimation of GFR in type 2 diabetic patients. Kidney Int 2002; 61: 1453-61.

[18] Herget-Rosenthal S, Marggraf G, Hüsing J, Göring F, Pietruck F, Janssen O, et al. Early detection of acute renal failure by serum cystatin C. Kidney Int 2004; 66: 1115-22.

[19] Spanaus KS, Kollerits B, Ritz E, Hersberger M, Kronenber F, von Ekardstein A. Serum creatinine, cystatin $C$, and beta-trace protein in diagnostic staging and predicting progression of primary nondiabetic chronic kidney disease. Clin Chem 2010; 56: 740-749.

[20] Dharnidharka VR, Kwon C, Stevens G. Serum cystatin C is superior to serum creatinine as a marker of kidney function: a meta-analysis. Am J Kidney Dis 2002; 40: 221-226.

[21] Nickolas TL, O'Rourke MJ, Yang J, Sise ME, Canetta PA, Barasch $\mathrm{N}$ et al. Sensitivity and specificity of a single emergency department measurement of urinary neutrophil gelatinase-associated lipocalin for diagnosing acute kidney injury. Ann Intern Med 2008; 148: 810-819.

[22] Viau A, El Karoui K, Laouari D, Burtin M, Nguyen C, Mori $\mathrm{K}$ et al. Lipocalin 2 is essential for chronic kidney disease progression in mice and humans. J Clin Invest 2010; 120:
$4065-4076$.

[23] Bolignano D, Lacquaniti A, Coppolino G, Donota V, Fazio MR, Nicocia G et al. Neutrophil gelatinase-associated lipocalin as an early biomarker of nephropathy in diabetic patients. Kidney Blood Press Res 2009; 32: 91-98.

[24] Vaidya VS, Niewczas MA, Ficociello LH, Johnson AC, Collings FB, Warran $\mathrm{JH}$ et al. Regression of microalbuminuria in type 1 diabetes is associated with lower levels of urinary tubular injury biomarkers, kidney injury molecule-1, and N-acetyl-beta-D-glucosaminidase. Kidney Int 2011; 79: 464-470.

[25] Han WK, Bailly V, Abichandani R, Thadhani R, Bonventre JV. Kidney injury molecule-1 (KIM-1): a novel biomarker for human renal proximal tubule injury. Kidney Int 2002; 62: 237-244.

[26] Ko GJ, Grigoryev DN, Linfert D, Jang HR, Watkins T, Cheadle $\mathrm{C}$ et al. Transcriptional analysis of kidneys during repair from AKI reveals possible roles for NGAL and KIM-1 as biomarkers of AKI to CKD transition. Am J Physiol Renal Physiol 2010; 298: F1472-F1483.

[27] Kamijo A, Sugaya T, Hikawa, Yamanouchi M, Hirata Y, Ishimitsu $\mathrm{T}$ et al. Clinical evaluation of urinary excretion of liver-type fatty acid-binding protein as a marker for the monitoring of chronic kidney disease: A multicenter trial. J Lab Clin Med 2005; 145: 125-33.

[28] Nakamura T, Sugaya T, Kawagoe Y, Uede Y, Osada S, Koedi H. Effect of pitavastatin on urinary liver-type fatty acid-binding protein levels in patients with early diabetic nephropathy. Diabetes Care 2005; 28: 2728-2732.

[29] Kamijo A, Sugaya T, Hikawa A, Yamanouchi M, Hirata Y, Ishimitsu $\mathrm{T}$ et al. Urinary liver-type fatty acid binding protein as a useful biomarker in chronic kidney disease. Mol Cell Biochem 2006; 284: 175-182.

[30] Kamijo A, Kimura K, Sugaya T, Yamanouchi M, Hikawa A, Hirano $\mathrm{N}$ et al. Urinary fatty acid-binding protein as a new clinical marker of the progression of chronic renal disease. J Lab Clin Med 2004; 143: 23-30.

[31] Wang G, Lai FM, Lai KB, Chow KM, Li KT, Szeto CC. Messenger RNA expression of podocyte-associated molecules in the urinary sediment of patients with diabetic nephropathy. Nephron Clin Pract. 2007; 106: c169-79.

[32] Cumming A. The renal system. In Doglas G, Nicol F \& Robertson C. Macleod's Clinical Examination. 11th International ed. Churchill Livingstone Elsevier;2005:p193.

[33] Alsaad KO, Herzenberg A M. Distinguishing diabetic nephropathy from other causes of glomerulosclerosis: an update. J Clin Pathol 2007 January;60(1):18-26.

[34] Bash LD, Selvin E, Steffes M, Coresh J, Astor BC. Poor Glycemic Control in Diabetes and the Risk of Incident Chronic Kidney Disease Even in the Absence of Albuminuria and Retinopathy: Atherosclerosis Risk in Communities (ARIC) Study. Archives of Internal Medicine 2008;168(22): $2440-2447$.

[35] American Diabetes Association Position Statement: Diabetic Nephropathy. Diabetes Care 2003 Jan;26(Suppl 1):S94-S98. 
[36] The ACE Inhibitors in Diabetic Nephropathy Trialist Group. Should all patients with type 1 diabetes mellitus and microalbuminuria receive angiotensin-converting enzyme inhibitors: a meta-analysis of individual patient data. Ann Intern Med 2001;134(5):370-379.

[37] Strippoli GFM, Bonifati C, Craig M, Navaneethan SD, Craig JC. Angiotensin converting enzyme inhibitors and angiotensin II receptor antagonists for preventing the progression of diabetic kidney disease (Cochrane Review). In: The Cochrane Library, Issue 4, 2006. London: Wiley.

[38] Kshirsagar AV, Joy MS, Hogan SL, Falk RJ, Colindres RE. Effect of ACE inhibitors in diabetic and nondiabetic chronic renal disease: a systematic overview of randomized placebo-controlled trials. Am J Kidney Dis 2000;35(4):695-707.

[39] Strippoli GFM, Craig M, Craig JC. Antihypertensive agents for preventing diabetic kidney disease (Cochrane Review). In: The Cochrane Library, Issue 4, 2006. London: Wiley.

[40] Mogensen CE, Neldam S, Tikkanen I, Oren S, Viskoper R, Watts RW, et al. Randomised controlled trial of dual blockade of the renin-angiotensin system in patients with hypertension, microalbuminuria, and non-insulin dependent diabetes: the Candesartan and Lisinopril Microalbuminuria (CALM) study. BMJ 2000;321:1440-4.

[41] Schjoedt KJ, Jacobsen P, Rossing K, Boomsma F, Parving HH. Dual blockade of the renin-angiotensin-aldosterone system in diabetic nephropathy: the role of aldosterone. Horm Metab Res 2005;37(Suppl. 1):4-8.

[42] Parving HH, Persson F, Lewis JB, Lewis EJ, Hollenberg NK; AVOID Study Investigators. Aliskiren combined with losartan in type 2 diabetes and nephropathy. N Engl J Med 2008;358:2433-2446.

[43] Yusuf S, Teo KK, Pogue J, Dyal L, Copland I, Schumacher H et al; ONTARGET Investigators. Telmisartan, ramipril, or both in patients at high risk for vascular events. N Engl J Med 2008;358:1547-1559.

[44] National Kidney Foundation. KDOQI Clinical Practice Guideline for Diabetes and CKD: 2012 update. Am J Kidney Dis. 2012;60(5):850-886.

[45] Kunz R, Friedrich C,Wolbers M, Mann JF. Meta-analysis: effect of monotherapy and combination therapy with inhibitors of the renin angiotensin system on proteinuria in renal disease. Ann Intern Med 2008 Jan 1;148(1):30-48.

[46] Mann JF, Schmieder RE, McQueen M, Dyal L, Schumacher $\mathrm{H}$, Pogue J et al. Renal outcomes with telmisartan, ramipril, or both, in people at high vascular risk (the ONTARGET study): a multicentre, randomized, double blind, controlled trial. Lancet 2008 Aug 16;372(9638):547-553.

[47] Diabetes Control and Complications Trial Research Group: The effect of intensive treatment of diabetes on the development and progression of long-term complications in insulin-dependent diabetes mellitus. $\mathrm{N}$ Engl $\mathrm{J}$ Med 1993;329(14):977-986.

[48] UK Prospective Diabetes Study Group: Intensive blood glucose control with sulphonylureas or insulin compared with conventional treatment and risk of complications in patients with type 2 diabetes (UKPDS 33). Lancet 1998;352(9131):837-853.
[49] The Action to Control Cardiovascular Risk in Diabetes Study Group. Effects of intensive glucose lowering in type 2 diabetes. N Engl J Med 2008; 358:2545-2559.

[50] The ADVANCE Collaborative Group. Intensive blood glucose control and vascular outcomes in patients with type 2 diabetes. N Engl J Med 2008;358:2560-2572.

[51] Ismail-Beigi F, Craven T, Banerji MA, Basile J, Calles J, Cohen RM, et al. ACCORD Trial Group. Effect of intensive treatment of hyperglycaemia on microvascular outcomes in type 2 diabetes: an analysis of the ACCORD randomised trial. Lancet 2010;376:419-430.

[52] American Diabetes Association. Standards of medical care in diabetes-2011. Diabetes Care 2011;34(Suppl 1):S11-S61

[53] American Diabetes Association. Standards of medical care for patients with diabetes mellitus. Diabetes Care 2003;26(suppl 1):S33-50.

[54] UK Prospective Diabetes Study Group. Tight blood pressure control and risk of macrovascular and microvascular complications in type 2 diabetes: (UKPDS 38). BMJ 1998;317:703-713.

[55] Heart Outcomes Prevention Evaluation Study Investigators. Effects of ramipril on cardiovascular and microvascular outcomes in people with diabetes mellitus: results of the HOPE study and MICRO-HOPE substudy. Lancet 2000;355:253-259.

[56] Levey AS. Clinical practice. Nondiabetic kidney disease. N Engl J Med 2002;347:1505-1511.

[57] Hansen HP, Tauber-Lassen E, Jensen BR, Parving HH. Effect of dietary protein restriction on prognosis in patients with diabetic nephropathy. Kidney Int 2002;62:220-228.

[58] Kasiske BL, Lakatua JD, Ma JZ, Louis TA. A meta-analysis of the effects of dietary protein restriction on the rate of decline in renal function. Am J Kidney Dis 1998;31:954-961.

[59] Fouque D, Wang P, Laville M, Boissel JP. Low protein diets for chronic kidney disease in non diabetic adults (Cochrane Review).In: The Cochrane Library, Issue 4, 2000. London: Wiley

[60] Robertson L, Waugh N, Robertson A. Protein restriction for diabetic renal disease (Cochrane Review). In: The Cochrane Library, Issue 4, 2007. London: Wiley.

[61] Keane WF. The role of lipids in renal disease: future challenges. Kidney Int Suppl 2000;75:S27-31.

[62] Sukhija R, Bursac Z, Kakar P, Fink L, Fort C, Satwani S, et al. Effect of statins on the development of renal dysfunction. Am J Cardiol 2008;101(7):975-9.

[63] Fried LF, Orchard TJ, Kasiske BL. Effect of lipid reduction on the progression of renal disease: a meta-analysis. Kidney Int 2001;59:260-9.

[64] Canadian Diabetes Association Clinical Practice Guidelines Expert Committee. Canadian Diabetes Association 2008 clinical practice guidelines for the prevention and management of diabetes in Canada. Can J Diabetes 2008; 32: S95-S98. 
[65] Gaede P, Vedel P, Parving HH, Pedersen O. Intensified multifactorial intervention in patients with type 2 diabetes mellitus and microalbuminuria: the Steno type 2 randomised study. Lancet 1999;353(9153):617-622.
[66] Gaede P, Lund-Andersen H, Parving HH, Pedersen O. Effect of a multifactorial intervention on mortality in type 2 diabetes. N Engl J Med 2008;358(6):580-591. 